\title{
Recursos didácticos para el aprendizaje de la lectura a través del método Gleen Doman utilizando realidad aumentada
}

\section{Teaching resources for learning to read through the Gleen Doman method using augmented reality}

\author{
SILVA-MARTÍNEZ, Dalia†*, SÁNCHEZ-DÍAZ, Clara Aurora, LEÓN-PLATAS, Micaela Guadalupe
} y PARADA-SOSA, Jesús Enrique

Instituto Tecnológico de Oaxaca / Tecnológico Nacional de México

ID 1r Autor: Dalia, Silva-Martínez, ORC ID: 0000-0002-0561-6459, CVU CONACYT ID: 90232

ID $1^{\text {er }}$ Coautor: Clara Aurora, Sánchez-Díaz / ORC ID: 0000-0002-1149-454X, CVU CONACYT ID: 787254

ID $2^{\text {do }}$ Coautor: Micaela Guadalupe, León-Platas / ORC ID: 0000-0002-1336-5135, CVU CONACYT ID: 989117

ID $3^{\text {er }}$ Coautor: Jesús Enrique, Parada-Sosa / ORC ID: 0000-0001-6643-403, CVU CONACYT ID: 988003

\begin{abstract}
Resumen
Este artículo plantea el resultado de las pruebas realizadas así como el rediseño del material educativo y la aplicación móvil del proyecto "Recursos didácticos para el aprendizaje de la lectura a través del método Gleen Doman utilizado realidad aumentada". Los recursos didácticos tienen tres niveles: 1.-palabras (a través de tarjetas) y juegos tradicionales de mesa 2.relación de palabras en oraciones 3.-cuentos $\mathrm{Al}$ momento de realizar las prueba en el jardín de niños se encontró que existía conflicto ya que la aplicación en algunas ocasiones no reconocía el código $\mathrm{QR}$ asociado, debido a la distribución dentro del juego de mesa, para ello se cambió a un código de RA. Se modificó la distribución de los tableros de juegos, se cambió el material en que fueron realizados, se agregaron nuevas categorías basadas en campos semánticos que manejan los niños. Este proyecto está basado en un método global de aprendizaje de lectura, que se caracteriza porque los niños aprenden palabras completas agrupadas en campos semánticos. También se desarrolló un sistema de venta en línea (y con ello diferentes paquetes de venta, según las necesidades del cliente), así como del soporte técnico para el uso del producto.
\end{abstract}

Glenn Doman, Juegos tradicionales, Aplicación móvil

\begin{abstract}
This article presents the results of the tests carried out as well as the redesign of the educational material and the mobile application of the project "Teaching resources for learning to read through the Gleen Doman method using augmented reality". The teaching resources have three levels: 1.-words (through cards) and traditional board games 2.-relation of words in sentences 3.-stories at the moment to apply the tests in the kindergarten, it was found that there was conflict since the application was designed, because it sometimes did not recognize the associated QR code, due to the distribution within the board game, for this reason it was changed to an RA code. The distribution of the game boards was modified, the material in which they were made was changed, new categories were added based on semantic fields that children could handle. This project is based on a global method of reading learning, which is characterized by the fact that children learn complete words grouped in semantic fields. An online sales system was also developed (and with this different sales packages, according to the customer's needs), as well as technical support for the use of the product.
\end{abstract}

Glenn Doman, Traditional games, Mobile application

Citación: SILVA-MARTÍNEZ, Dalia, SÁNCHEZ-DÍAZ, Clara Aurora, LEÓN-PLATAS, Micaela Guadalupe y PARADA-SOSA, Jesús Enrique. Recursos didácticos para el aprendizaje de la lectura a través del método Gleen Doman utilizando realidad aumentada. Revista de Tecnología y Educación. 2019. 3-9: 1-8

$\dagger$ Investigador contribuyendo como primer autor. 


\section{Introducción}

El aprendizaje de la lectura es muy importante en los primero años de la vida escolar de un niño, ya que es la base para que pueda adquirir conocimientos en diferentes áreas. Hay muchos métodos de lectura que se han desarrollado. También hay diferentes materiales que se han desarrollado para estos aprendizajes, sin embargo muchos de ellos no logran captar la atención del niño debido que en épocas recientes la influencia de los medios de comunicación tanto impresos como digitales estimulan a los niños y eso hace que pierdan el interés en ciertos materiales didácticos tradicionales, se ha discutido mucho sobre si un niño debe usar o no un dispositivo móvil o a que edad debe usarlo.

A un niño no se le puede ocultar que la tecnología existe, ya que al negárselo prácticamente se hace más atractivo su uso, lo importante es usar la tecnología moderadamente y con un fin específico.

Este proyecto se apoya de la tecnología, pero fomenta su uso de forma responsable porque los padres, profesores y compañeros forman parte de este proceso de aprendizaje. Los recursos didácticos incluyen una aplicación móvil y juegos tradicionales forman un producto innovador que combina el pasado y el presente con visión hacia el futuro, hasta el momento no existen aplicaciones con realidad aumentada enfocadas a que los niños aprendan a leer, esto plantea un área importante para la innovación en cuanto a materiales didácticos.

En Google Play y App Store se pueden encontrar aplicaciones gratuitas o de paga que apoyan en el aprendizaje de la lectura, sin embargo la mayoría se basa en métodos sintéticos y el modelo educativo 2017 tiene un enfoque constructivista haciendo uso de métodos analíticos o globales; cabe recalcar que ninguna de estas aplicaciones implementa realidad aumentada y no lleva al niño a interactuar con su entorno, es decir todo el contenido que se visualiza es bidimensional a pesar de que tenga sonido o imágenes y no cuentan con material físico que permita que el niño complemente su desarrollo mental.
La primera versión de este material didáctico se publicó en el Libro Puerto del Conocimiento: Expociencias Nacional 2017, con el título de "ARGLeenD", después de esa participación se siguieron desarrollando pruebas con niños que estaban aprendiendo a leer y escribir y se detectó ciertas áreas de oportunidad donde mejorar el proyecto y pasar a la siguiente fase del prototipo.

\section{Métodos para la enseñanza de la lectura}

Existen diferentes métodos para la enseñanza de la lectura y se clasifican en métodos sintéticos y analíticos o globales de lectura donde su diferencia principal es la clasificación de las palabras en campos semánticos y su metodología de enseñanza.

El método sintético, se sustenta en el análisis parte de conocer primero las letras $\mathrm{y}$ sonidos, fragmentando la palabra, y luego va uniendo en sílabas, posteriormente en palabras, y finalmente se unen las palabras (Pérez 2012).

Dentro de los métodos sintéticos está:

- El método alfabético (parte de la memorización de las letras, aún cuando el nombre de las letras no corresponde al resultado de unir esas letras).

Fónico(no se enseña el nombre de la letra, si no su sonido, así al unir la letras van leyendo la palabra).

Silábico (enseña por sílabas, donde cada consonante se une con las vocales y después une las silabas para formar palabra) (Pérez 2012).

El método analítico o global plantea el aprendizaje de la palabra completa asociando un significado, posteriormente por deducción se aprenden los sonidos de las letras y sílabas, normalmente se enseña con imágenes para lograr asociaciones. Logrado una mejor comprensión de lo que se lee, porque se aprenden palabras asociadas a un significado.

Dentro del método global está el método Gleen Doman, también conocido como método filadelfia, el cual consiste en sesiones donde se muestran al niño tarjetas donde se escriben bits, estos bits pueden ser palabras, para de palabras o frases. 


\section{Características de los recurso didácticos}

Este proyecto combina el desarrollo de una aplicación móvil con realidad aumentada ( lo que permite que el usuario de aplicación móvil pueda interactuar con su entorno, haciendo que el niño no se quede solo sentado jugando con el dispositivo si no que se relaciona con padres, hermanos, compañeros de clase para poder jugar haciendo que se aprenda jugando y socializando), además se incluye material físico (como lo tableros de los juegos de mesa, las tarjetas, así como los cuentos) permite no solo ir mejorando la aplicación, sino también adaptar el material físico (ver figura 1).

Cuenta con 3 niveles:

El primer nivel es la identificación de palabras y el uso de los juegos de mesa tradicionales (memorama, lotería y serpientes y escaleras).

El segundo es la relación de estas palabras en oraciones.

El tercero es la integración de textos a través de cuentos dentro de la cual se incluye una sección post-cuento que consiste en responder preguntas sobre la lectura de estos.

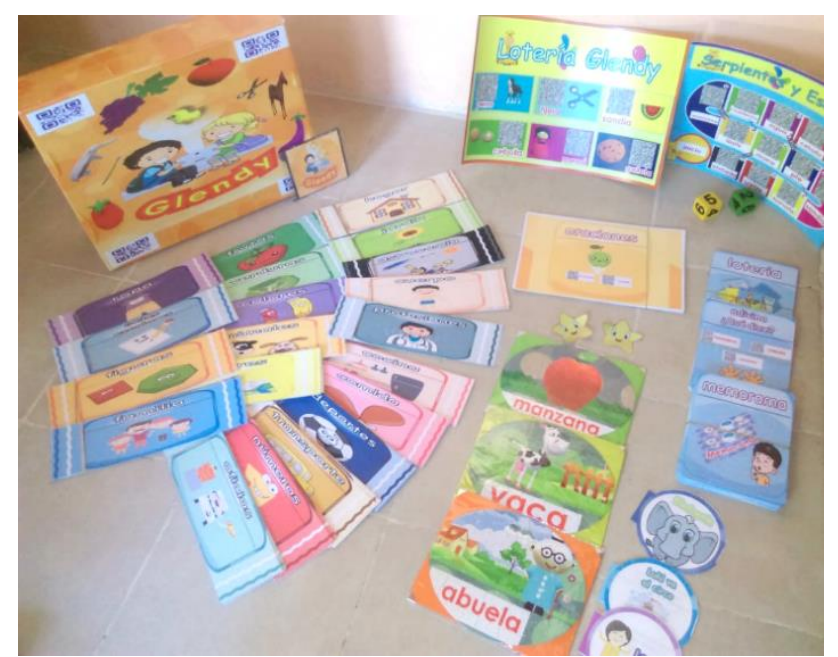

Figura 1 Material físico del proyecto

\section{Tecnologías a usar}

La Realidad Aumentada (RA), consiste en sobreponer objetos o animaciones generadas por computadora sobre la imagen en tiempo real que recoge una cámara web. (CeDiCyT, 2018). Para el desarrollo de la realidad aumentada se utilizó Unity, que es un motor de videojuego multiplataforma creado por Unity Technologies.
Unity está disponible como plataforma de desarrollo para Microsoft Windows, OS X, Linux. La plataforma de desarrollo tiene soporte de compilación con diferentes tipos de plataformas (UNITY 201).

Vuforia es un kit de desarrollo de aplicaciones que utilicen realidad aumentada en dispositivos móviles utilizando la tecnología de visión artificial para reconocer y rastrear imágenes planas y objetos 3D simples, como cajas, en tiempo real. (Vuforia, 2018).

Para el desarrollo de la aplicación se utilizó JAVA Script, que es un lenguaje muy usado en el desarrollo de software.

\section{Metodología}

Para este proyecto se utilizó el desarrollo por prototipos, ya que permite hacer mejoras después de probar el prototipo y así ir perfeccionado el proyecto.

\section{Desarrollo del Proyecto}

Al momento de probar el primer prototipo se encontró que los niños al utilizar el dispositivo móvil, lo movían mucho y en ocasiones la cámara captaba dos códigos $\mathrm{QR}$, y por lo tanto reproducía ambos sonidos, o en alguno casos no reconocía adecuadamente el código causando confusión en los niños (figura 2).

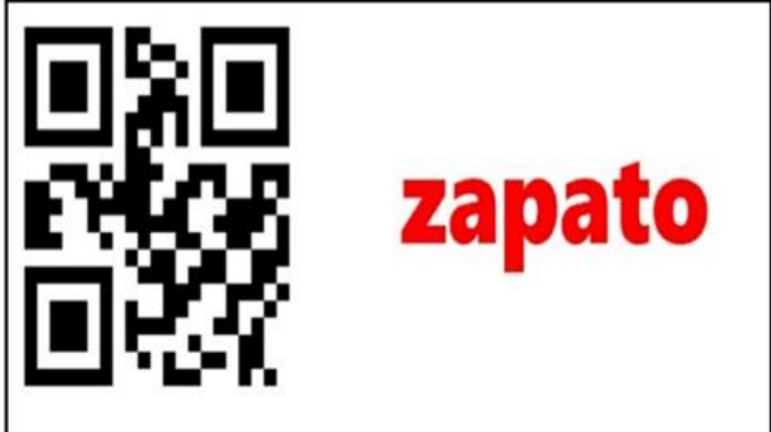

Figura 2 Tarjeta usada en el primer prototipo

Por ello se optó por cambiar el código QR (figura 1) por códigos de realidad aumentada (figura 3), esto terminó con el problema de la confusión del reconocimiento del código.

Los código de realidad aumentada, por sus diseño permite que reconozca patrones de figuras geométricas haciendo que la precisión sea mayor. 


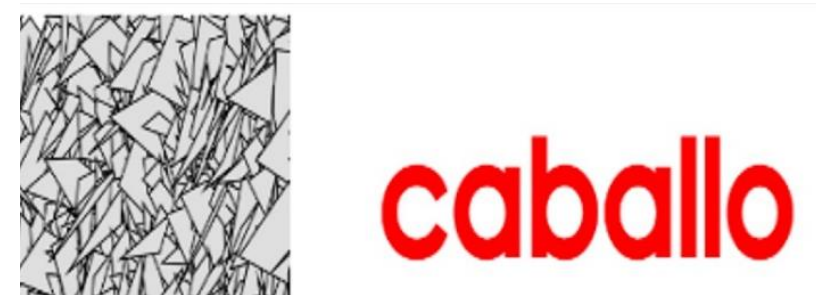

Figura 3 Diseño de las tarjetas de palabras

En la figura 4 se aprecia la parte posterior de la categoría animales, en total se hicieron 20 categorías. Una categoría son bits(palabras) que deben tener cierta relación entre sí, logrando que el niño aparte de aprender el Bit, aprenda los demás datos que se le relacionan a este.

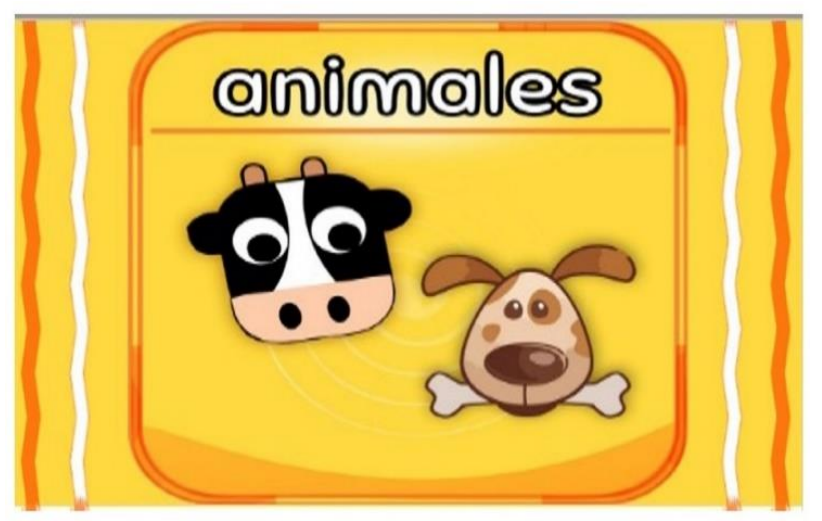

Figura 4 Juego de tarjetas según categorías

Para el desarrollo de la realidad aumentada se utilizó Unity y Vuforia, donde se creó una animación por computadora para cada tarjeta (cada tarjeta tiene un bit de información). Esta animación tiene diferentes vistas, de tal manera que cuando el niño mueva la tableta pueda ver diferentes ángulos de la imagen. En la figura 5 se observa la imagen abuelo de la categoría familia.

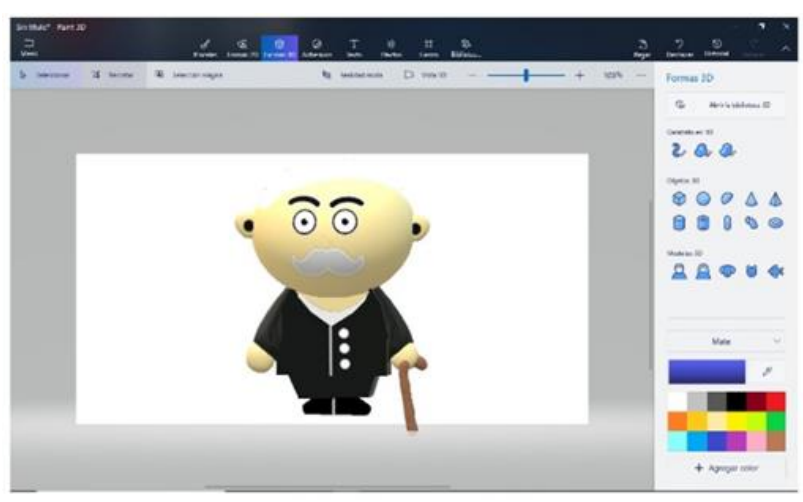

Figura 5 Animación por computadora
En la figura 6 se ve el diseño de las tarjetas de las oraciones que es el siguiente nivel de proyecto, hasta aquí solo se habían diseñado tarjetas con palabras, en las oraciones los niños aprenden significados.

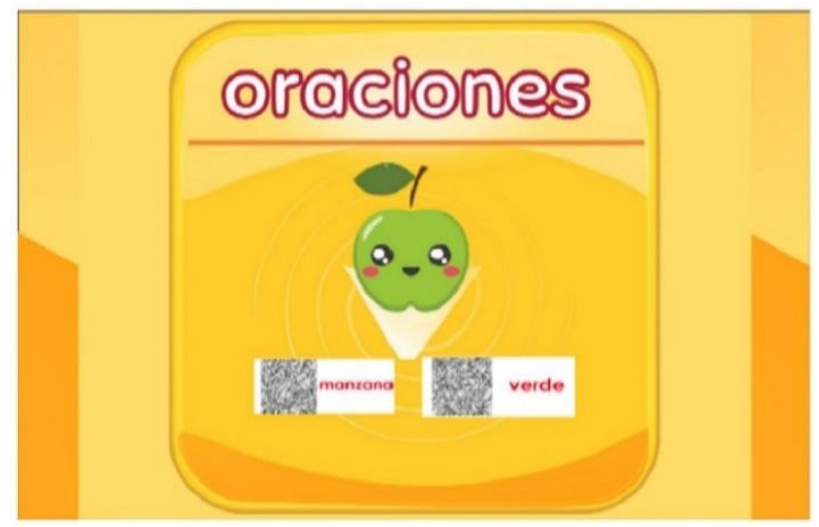

Figura 6 Tarjetas de oraciones

En la figura 7 se encuentran las oraciones con su respetivo código de realidad aumentada. Se crearon juegos de oraciones donde se incluyeron palabras de las 20 categorías anteriormente descritas.

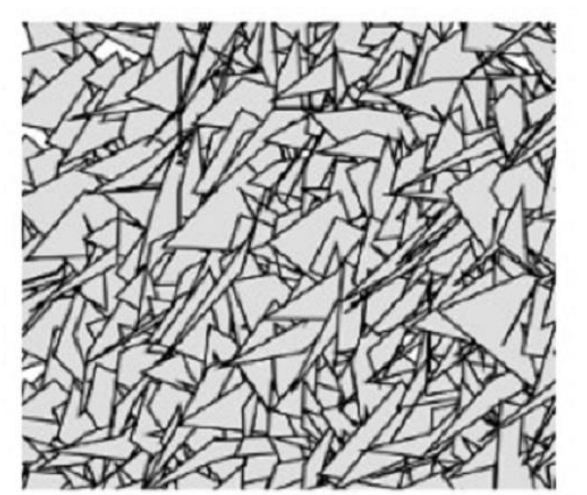

\section{Mi perro anda en bicileta}

Figura 7 Oración con su código de realidad aumentada

\section{El desarrollo de la aplicación}

La figura 8 muestra el proceso del funcionamiento de la aplicación. Primero, el usuario elige alguna de las categorías mostradas, al seleccionarla, se abre una escena que espera reconocer los targets que están en las tarjetas, al reconocerlo, busca en la base de datos y esta le devuelve el modelo al que está asociado dicha tarjeta para que lo muestre en pantalla. 


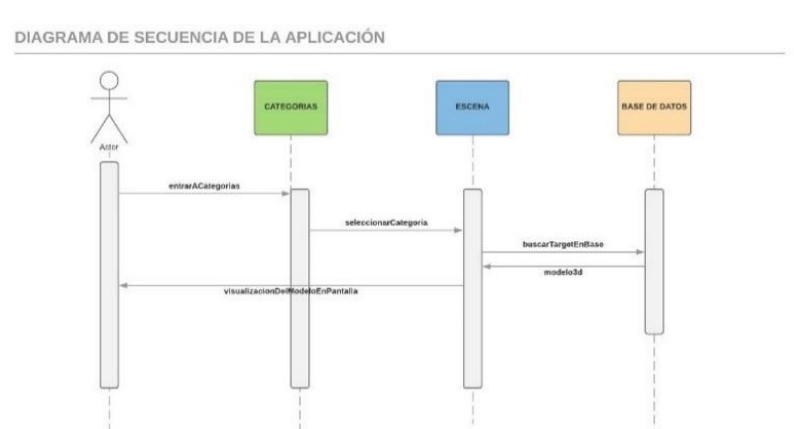

Figura 8 Diagrama de proceso de la aplicación

Para que la aplicación muestre la animación al momento de reconocer el código de realidad aumentada fue necesario crear la base de datos (figura 9).

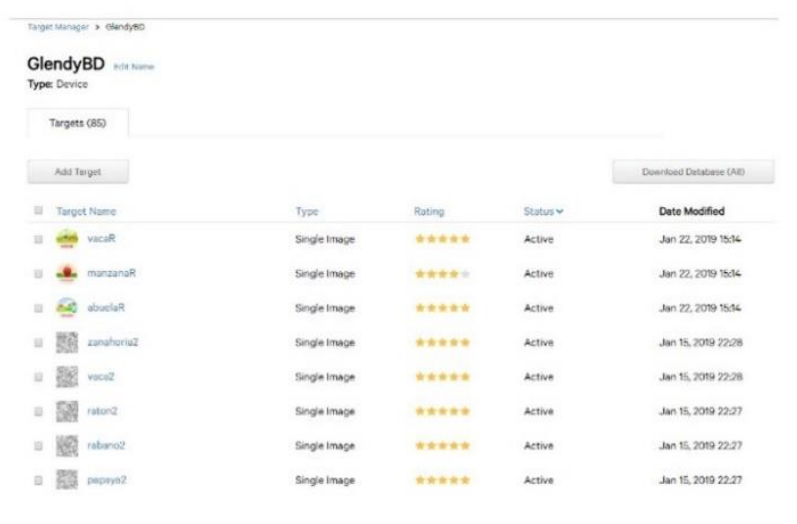

Figura 9 Creación de la base de datos en Vuforia

Para que la aplicación de realidad aumentada funcionara, se grabaron los sonidos de las categorías que se aumentaron en este prototipo, y se crearon las escenas en Unity para lograr que el niño logre asociar la palabra escrita con una imagen tridimensional que no se encuentra en la tarjeta, pero que puede ver a través de la cámara del dispositivo por medio de la realidad aumentada, y también pueda escuchar cómo se pronuncia esa palabra (figura $10)$.

Lo anterior da un significado a la palabra asociándola a una imagen, de tal manera que cada vez que el niño vea la palabra tenga un referente tanto visual como auditivo.

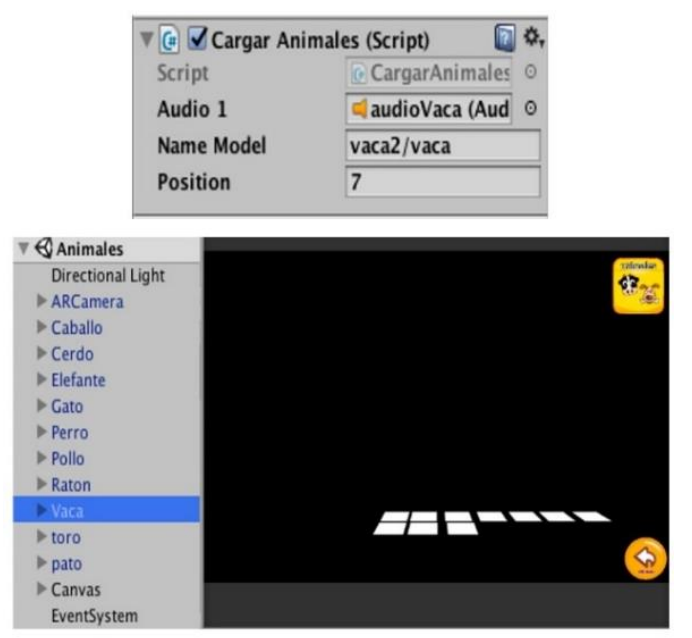

Figura 10 Escena Unity de la categoría animals

Para el desarrollo de las oraciones (Ver figura 11) se siguió el mismo procedimiento que para la categorías de palabras, asociando una sola imagen tridimensional a cada oración.

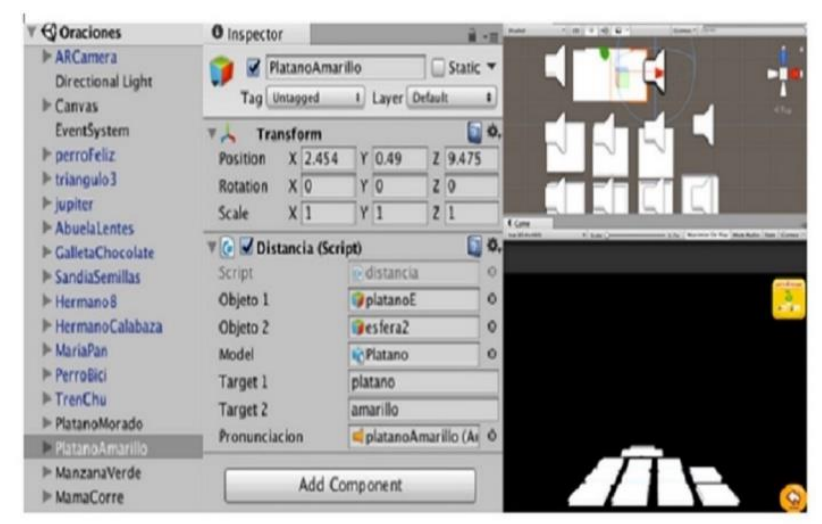

Figura 11 Escena Unity de la categoría oraciones

En la figura 12 es una captura de pantalla tomada desde el dispositivo móvil al momento que la cámara detecta la tarjeta de la categoría animales. En esta imagen se observa que una persona sostiene la tarjeta mientras el niño toma el dispositivo y observa a través de la pantalla la imagen que se proyecta y escucha el audio con la palabra escrita.

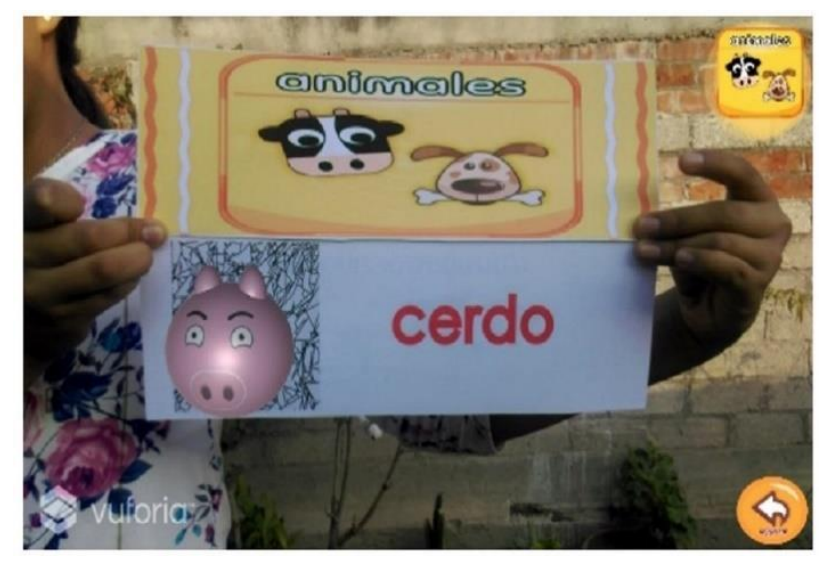

Figura 12 Imagen tridimensional de la categoría animales con el bit cerdo

SILVA-MARTÍNEZ, Dalia, SÁNCHEZ-DÍAZ, Clara Aurora, LEÓNPLATAS, Micaela Guadalupe y PARADA-SOSA, Jesús Enrique. Recursos didácticos para el aprendizaje de la lectura a través del método Gleen Doman utilizando realidad aumentada. Revista de Tecnología y Educación. 2019 
El desarrollo de cuentos es muy importante en este proyecto, así que se incluyeron 6 cuentos donde los niños unen oraciones para comprender historias (figura 13).

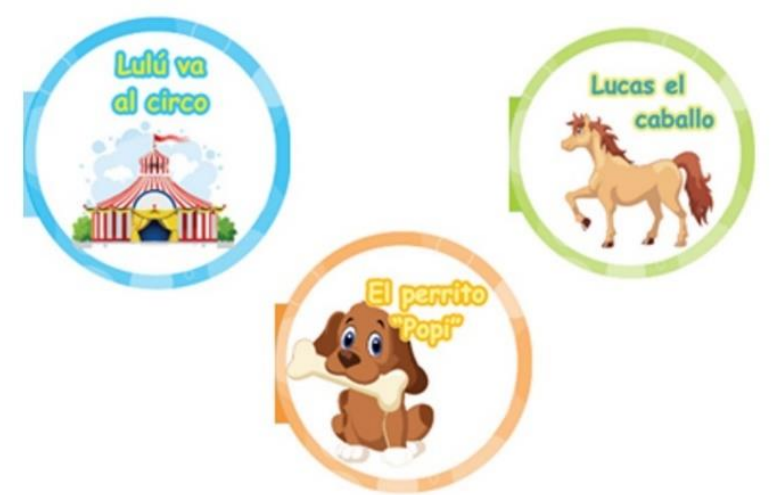

Figura 13 Cuentos

Todas las páginas del cuento tienen imágenes tridimensionales acordes a la temática del cuento, buscando captar la atención del niño.

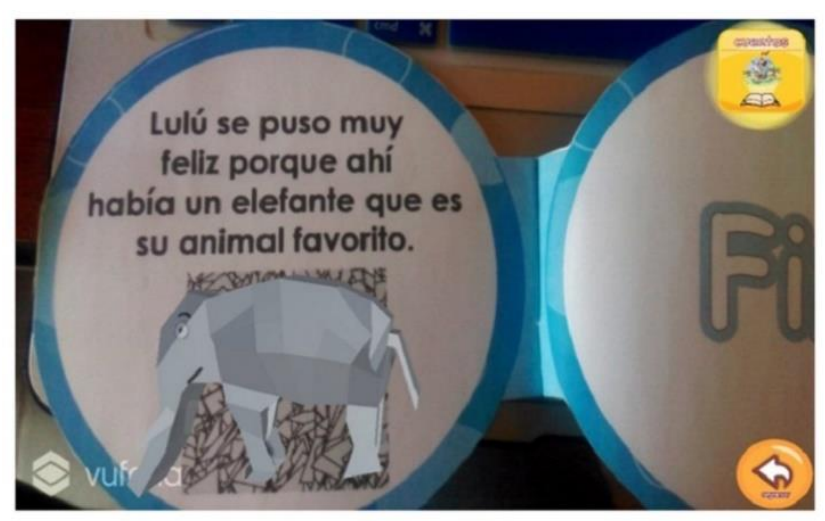

Figura 14 Imagen tridimensional del cuento titulado "el circo"

Una vez que el niño pueda terminar el cuento, se diseñó una sección poscuento, donde se realizan preguntas al niños acerca de la trama del cuento, propiciando que el niño recuerde y comprenda lo que leyó (figura 15).

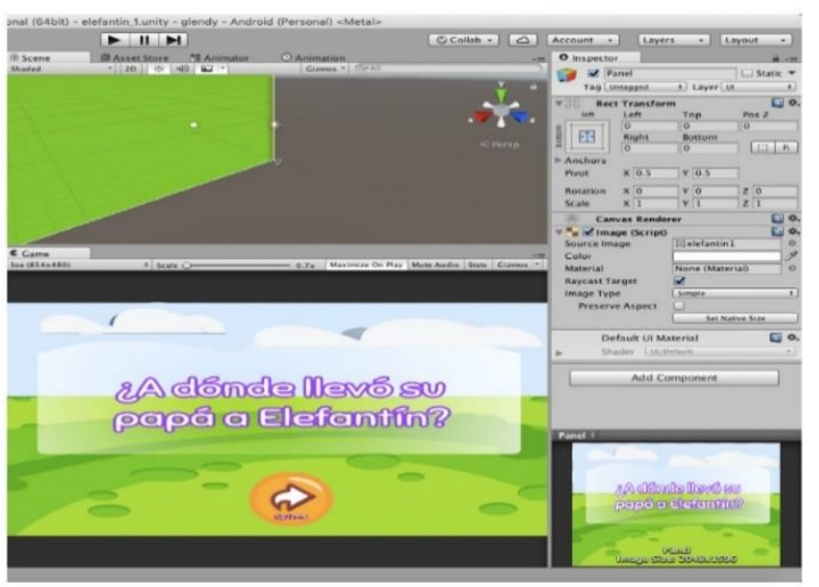

Figura 15 Sección poscuento

\section{Desarrollo de los juegos en la aplicación}

Los juegos que se desarrollaron incluyen lotería y funciona como la lotería tradicional, con las tarjetas y los tableros, el rediseño que se realizó fue que los tableros eran en papel, después de las primeras pruebas se hicieron en lona, pero al momento de jugar y debido a que la superficie no es lisa, la aplicación tenía dificultades para leer (figura 16).

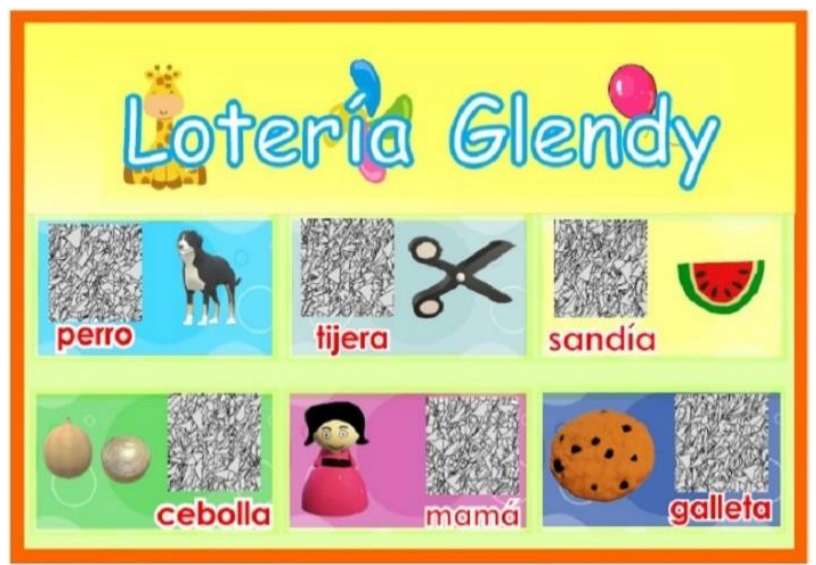

Figura 16 Lotería

Después se optó por una impresión en cartón grueso dando mejores resultados que la impresión en lona, de tal manera que todos los tableros a usar como serpientes y escaleras,(ver figura 17) así como el memorama (figura 18).

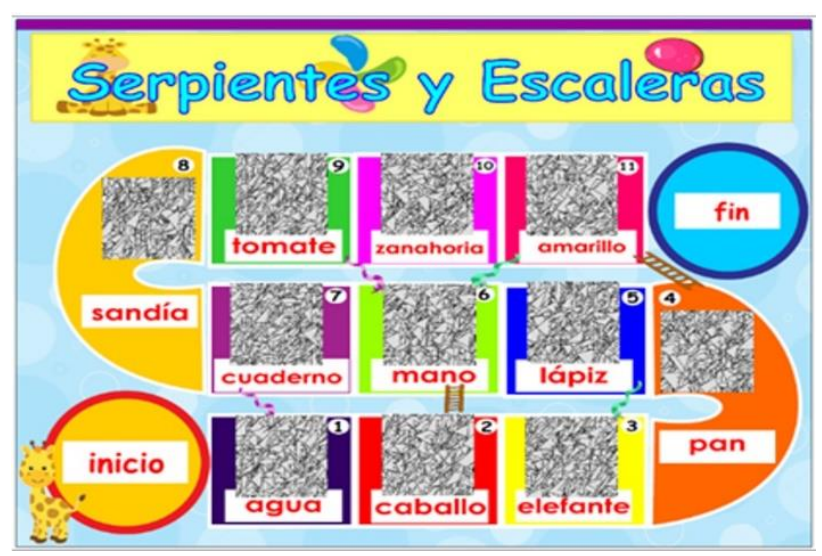

Figura 17 Serpientes y escaleras

En el juego de memorama el niño debe encontrar las tarjetas iguales y mostrarlas a la cámara del dispositivo para que la aplicación pueda detectar si los dos códigos son iguales y con ello otorgar estrellas al niño. 


\section{menopana}

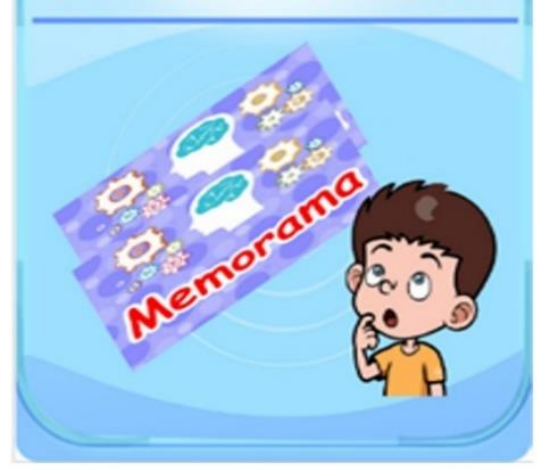

Figura 18 Memorama

Por cada juego de palabra que el niño adivine y dependiendo de la cantidad de intento que realiza se le dan estrellas, con diferente puntaje, que al sumarlas dan su puntaje total en el juego (ver figura 19)

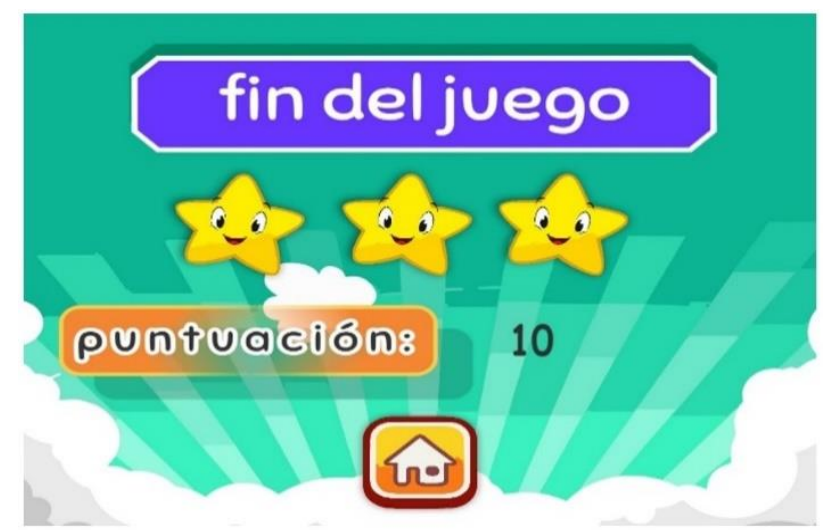

Figura 19 Puntuación del juego

La aplicación además de reconocer códigos de realidad aumentada, también reconoce imágenes planas, de tal manera que el niño al armar el rompecabezas, puede enfocar la cámara al rompecabezas armado y ver la figura tridimensional y escuchar el sonido (figura 20).

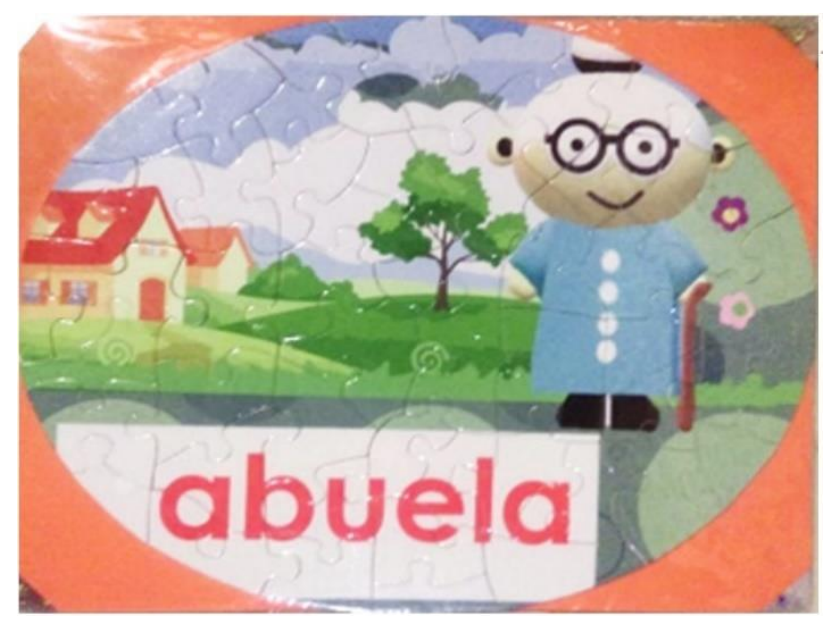

Figura 20 Rompecabezas
Se diseño otro juego que funciona con las tarjetas de las diferentes categorías, esta consiste en pedirle al niño que encuentre una tarjeta determinada y que la muestre a la pantalla del dispositivo móvil (figura 21).

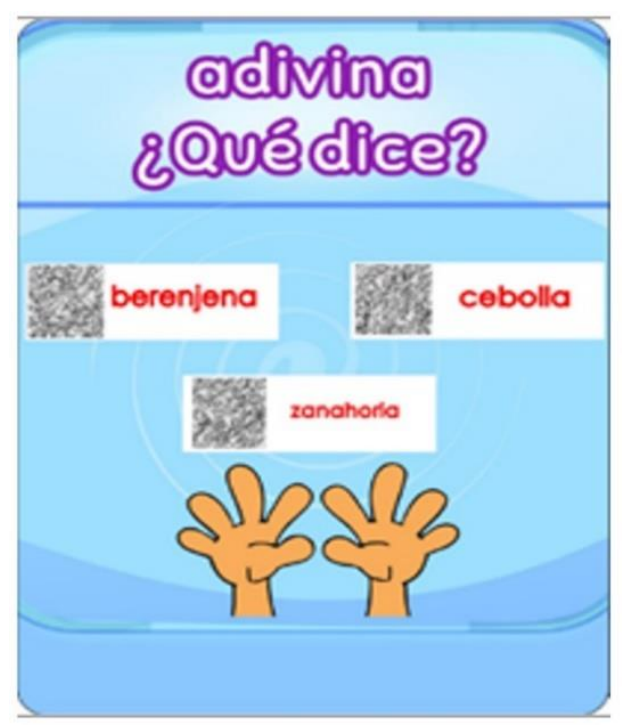

Figura 21 ¿Adivina que dice?

En el primer prototipo era por medio de un menú, que aunque era grafico también era estático por lo que se pensó en otra alternativa.

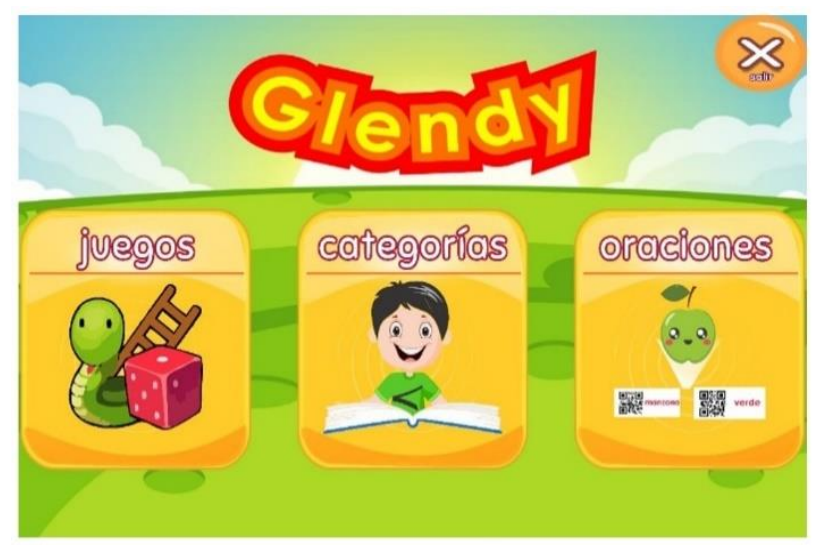

Figura 22 Interfaz de la aplicación

Una vez que se rediseñaron los juegos, se procedió a cambiar el diseño de la interfaz de la aplicación, para ello se optó por un carrusel donde el niño puede desplazar la pantalla con el dedo y seleccionar la opción que desee (ver figura 22).

También en la interfaz de juegos se optó por un carrusel (ver figura 23). 


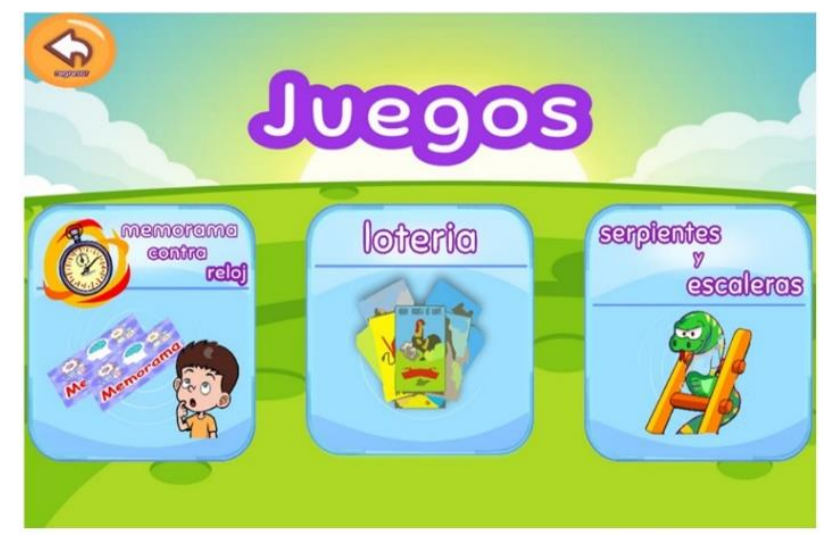

Figura 23 Interfaz de juegos

\section{Conclusiones}

En la introducción se planteó el desarrollo de recursos didácticos para el aprendizaje de la lectura, se discutió brevemente los métodos que existen para aprender a leer y la diferencia de ellos.

También se describió brevemente el tipo de tecnología a usar en el desarrollo de la aplicación móvil.

La metodología de prototipo permitió realizar correcciones sobre la marcha y una vez que se iba probando, ya que no se tenía la idea clara de cómo debía estar el producto terminado.

Se logró rediseñar el prototipo, tanto en los materiales físicos como en la aplicación móvil a partir de los resultados obtenidos de las pruebas realizadas con niños.

Como se mencionó anteriormente el diseño de recursos didácticos es un área de oportunidad donde la creatividad y el ingenio pueden ser un aliado importante para lograr en niños aprendizajes lúdicos, y que además puedan compartir en familia, con compañeros de clase o con amigos.

\section{Referencias}

CeDiCyT. (2018). ¿Qué es la realidad aumentada? Obtenido de Centro de Difusión de Ciencia y Tecnología: http://www.cedicyt.ipn.mx/RevConversus/Pagi nas/RealidadAumentada.aspx

Doman, G. (2015). Cómo enseñar a leer a su bebé. Edaf.
Escudero, E. B., Lira, R. V., Roldán, S. C., Meneses, J. C., \& Jiménez, J. R. (2017). Cambios y tendencias del aprendizaje en México: 2000-2015. Obtenido de Publicaciones INEE:

http://publicaciones.inee.edu.mx/buscadorPub/P 1/C/156/P1C156.pdf

Secretaria de Educacion Publica. (2017). Aprendizajes Clave. (S. d. Pública, Ed.) Recuperado el 19 de octubre de 2018, de Secretaria de Educación Publica: https://www.aprendizajesclave.sep.gob.mx/desc argables/biblioteca/preescolar/1LpM-

Preescolar-DIGITAL.pdf

Perez, O. C. (2012). Métodos de enseñanza de la lectoescritura en la Educación Primaria: Didáctica de la lectoescritura en la educación primaria. España: Editorial Académica Española.

Unity. (2018). Unity Technologies. Obtenido de Unity https://unity3d.com/es/unity

Vuforia. (2018). Vuforia. Obtenido de Vuforia: https://www.vuforia.com/ 